\title{
Gesamtverzeichnis des
}

\section{deutschsprachigen Schriftums (GV)}

$$
1700-1910
$$

Bearbeitet unter der Leitung von

Hilmar Schmuck und Willi Gorzny

Bibliographische und redaktionelle Beratung:

Hans Popst und Rainer Schöller

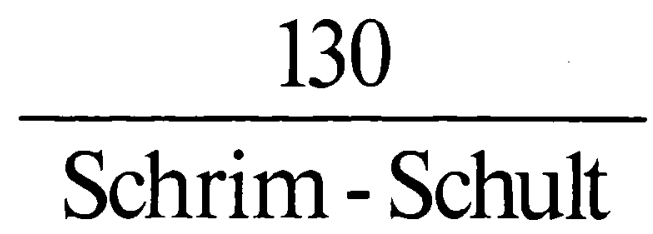

K $\cdot G \cdot$ Saur München $\cdot$ New York $\cdot$ London $\cdot$ Paris 1985 
CIP.Kurztitelaufnahme der Deutschen Bibliothek

Gesamtverzeichnis des deu tschsprachigen Sch rifttums : (GV). - München, New York, London, Paris : Saur.

Bd. 1 - 6 bearb. unter d. Leitung von Peter Geils u. Willi Gorzny.

ISBN 3-598-30000-X

$1700-1910$ / bearb. unter d. Leitung von Hilmar Schmuck u. Willi Gorzny. Bibliograph, u. red. Beratung: Hans Popst u. Rainer Schöller

NE: Schmuck, Hilmar [Bearb.]

130. Schrim - Schult. - 1985.

(C) 1985 by K. G. Saur Verlag KG, München

Techn. Realisierung und Druck: Norbert Gärtner, Mainz-Kastel

Binden: Karl Schaumann, Darmstadt

Printed in the Federal Republic of Germany

ISBN 3-598-30000-X (Gesamtwerk) 